\title{
Los límites al derecho de autor en el comercio internacional: una fórmula para la búsqueda del bien común en los procesos de integración económica*
}

\author{
Limits to copyright in international trade: \\ a formula for seeking the common good \\ in economic integration processes
}

\section{Juan F. Córdoba Marentes** \\ María Carmelina Londoño L.****}

\section{RESUMEN}

La propiedad intelectual es uno de los temas más debatidos en los procesos de integración económica, como lo demuestran las negociaciones detrás del ADPIC, el ACTA y el TPP. Una de las razones de estos desacuerdos obedece a que los procesos integracionistas se fundan primariamente en luchas de poder. El presente artículo propone una visión del derecho de autor que facilita la armonización de los intereses de los diversos actores participes en estos procesos internacionales. El estudio aboga por la reivindicación de la noción de bien común como pieza clave en el ejercicio que busca conciliar las exigencias tantas veces discordantes y contradictorias entre los diversos Estados, los autores, los usuarios y, en general, los grupos de interés.

PALABRAS CLAVE: Derecho de autor, propiedad intelectual, excepciones y limitaciones, integración económica, derechos humanos, bien común, ADPIC, ACTA, TPP, Conferencia de Marrakech.

\begin{abstract}
Intellectual property has been one of the most debated issues in economic integration processes, as the negotiations after the TRIPS, ACTA and TPP demonstrate. One of the main reasons of such disagreements is due to a lack of real common benefits at the base of the alliances. Instead, integration processes are mainly based on power struggles. This paper proposes a view of copyright that facilitates the harmonization of the various actors' interests participating in this kind of international processes. This framework, the study calls for the recovery of the notion of common good as a key factor in seeking the reconciliation of the most often conflicting demands among States, authors, users and interest groups.
\end{abstract}

KEY WORDS: Copyright, intellectual property, exceptions and limitations, economic integration, human rights, common good, TRIPS, ACTA, TPP, Marrakech Conference.

\footnotetext{
* Recibido: 20 de marzo de 2013. Aceptado: 30 de mayo de 2013.

** Director del Programa de Derecho en la Facultad de Derecho y Ciencias Políticas de la Universidad de La Sabana, Colombia (juan.cordoba@unisabana.edu.co).

*** Directora de la Maestría en Derecho Internacional de la Universidad de La Sabana, Colombia. (maria.londono1@unisabana.edu.co).
} 


\section{Sumario}

1. Introducción

2. El componente de propiedad intelectual en los tratados comerciales internacionales

3. El lugar de las excepciones y limitaciones en el estatuto de protección al derecho de autor

A) El derecho de autor como derecho de propiedad: la exaltación de un derecho subjetivo absoluto

B) El derecho de autor desde una perspectiva "moderna" de los derechos humanos

c) Una nueva visión del derecho de autor, sus excepciones y limitaciones

4. La reivindicación de la noción de bien común: una alternativa para conciliar el derecho de autor y los derechos humanos

A) Introducción del concepto de bien común: el paulatino abandono de las categorias individualistas

B) El derecho de autor y sus límites en el marco del bien común.

5. Colofón: algunas consecuencias prácticas de la conjugación del derecho de autor y el bien común en los procesos de integración económica

\section{Introducción}

La propiedad intelectual es uno de los temas que ha generado mayor debate en los procesos de integración económica de las últimas décadas. Así lo demuestra la historia del proceso que dio lugar al Acuerdo sobre los Aspectos de los Derechos de Propiedad Intelectual Relacionados con el Comercio (ADPIC o TRIP's por sus siglas en inglés), ${ }^{1}$ las más recientes negociaciones para la creación de un instrumento internacional para combatir la piratería y la falsificación de creaciones protegidas, el Anti-Counterfeiting Trade Agreement (en adelante AcTA), ${ }^{2}$ así como el proceso que se ha seguido para acordar el texto del Trans Pacific Partnership (en adelante TPP). ${ }^{3}$

De conformidad con el ADPIC, el término "propiedad intelectual" abarca tanto al derecho de autor (o copyright) como a la propiedad industrial. Las tensiones no escapan a ninguna de las dos categorías específicas y, aunque resulte contradictorio, la explicación de los más serios desacuerdos obedece a que por encima

\footnotetext{
1 Anexo 1c del Acuerdo de Marrakech, con el cual se creó la Organización Mundial de Comercio (omc). Para una explicación amplia de los antecedentes, negociaciones y desarrollo del ADPIC véase MaTtHEWs, Duncan. Globalising Intellectual Property Rights: The tRIPS Agreement, Routledge, Nueva York, 2002, pp. 7-106.

2 Anti-Counterfeiting Trade Agreement. Véase el texto oficial definitivo en el sitio Web de la Comisión Europea: http://trade.ec.europa.eu/doclib/docs/2011/may/tradoc_147937.pdf.

${ }^{3}$ Véanse los documentos de las propuestas en el sitio de Knowledge Ecology International: http://keionline.org/ node/1516; http://keionline.org/sites/default/files/tpp-10feb2011-us-text-ipr-chapter.pdf.
} 
de una alianza para un verdadero beneficio común, los procesos integracionistas se fundan primariamente en luchas de poder. Como una alternativa que favorezca el logro de acuerdos comerciales realmente integradores, el presente artículo propone una visión del derecho de autor que facilita la armonización de los intereses de los diversos actores partícipes en estos procesos internacionales.

La propuesta parte de un análisis crítico de la concepción tradicional y predominante del derecho de autor y, a partir de allí, define los contornos propios de este derecho para justificar el lugar que tienen las limitaciones y excepciones en dicho régimen. Dentro del marco que proporciona esta nueva perspectiva, el presente estudio aboga por la reivindicación de la noción de bien común como pieza clave en el ejercicio que busca conciliar las exigencias tantas veces discordantes y contradictorias entre los diversos Estados, los autores, los usuarios y, en general, los grupos de interés.

El objeto descrito se desarrollará de manera escalonada a lo largo de este trabajo. Así, el primer acápite apunta a describir brevemente algunos aspectos que evidencian la relevancia de la propiedad intelectual, y más específicamente el derecho de autor, en los foros multilaterales que promueven los acuerdos comerciales interestatales. El segundo acápite advierte sobre algunas dificultades que surgen de una concepción individualista y liberal del derecho de autor; a partir de esa aproximación crítica se plantea una propuesta que concilia las exigencias de este derecho con las demandas individuales y colectivas que se le oponen en el contexto que ofrece su naturaleza y la noción de acervo común. Introducida esta nueva propuesta, el tercer acápite rescata la importancia del bien común y sus exigencias, destacando su papel como un centro para la articulación de sinergias que favorecen los acuerdos integracionistas. Sobre la base de las reflexiones propuestas, en el colofón se recogen algunos criterios prácticos que pueden contribuir a la interpretación y aplicación de normas internacionales más afines con el verdadero propósito de cooperación e integración comercial que presumiblemente persiguen los instrumentos internacionales en esta materia.

\section{El componente de propiedad intelectual en los tratados comerciales internacionales}

En el ámbito multilateral, aún se escuchan los ecos de las voces a favor y en contra del ADPIC, en el cual se generó un estrecho vínculo entre la protección de la propiedad intelectual y el comercio internacional. El propósito fundamental del Acuerdo era proveer a los titulares de propiedad intelectual y entidades en- 
cargadas de su gestión, con medios eficaces para hacer respetar sus derechos. ${ }^{4}$ Aunque el interés inicial que manifestaron los países desarrollados fue el de incluir normas protectoras de la propiedad intelectual que combatieran las falsificaciones de productos protegidos por ésta, lo cierto es que el resultado final llegó más lejos. La propiedad intelectual terminó constituyéndose en un tercer pilar del Acuerdo de Marrakech con el que se creó la Organización Mundial de Comercio -adicional al de comercio de bienes y el intercambio de servicios $-{ }^{5} \mathrm{y}$, además, el ADPIC se convirtió en el instrumento internacional que más asuntos de propiedad intelectual comprende ${ }^{6}$ y el que con mayor alcance los trata. ${ }^{7}$

Sin embargo, al lado de los altos estándares de protección consagrados en el ADPIC, también se previeron algunos criterios de interpretación y aplicación de las normas allí contenidas, criterios que algunas veces son minusvalorados y, otras tantas, simplemente inaplicados. En particular, es de resaltar lo expresado en el preámbulo, en cuanto a la aplicación del Acuerdo "con la máxima flexibilidad requerida"; en el artículo 7, que dispone que "[l]a protección y la observancia de los derechos de propiedad intelectual deberán contribuir a la promoción de la innovación tecnológica y a la transferencia y difusión de la tecnología, en beneficio recíproco de los productores y de los usuarios de conocimientos tecnológicos y de modo que favorezcan el bienestar social y económico y el equilibrio de derechos y obligaciones", y en los principios establecidos en el artículo 8, que permite "promover el interés público en sectores de importancia vital", así como "prevenir el abuso de derechos de propiedad intelectual por sus titulares". Aunque algunos de estos criterios se tuvieron en cuenta en la Declaración Ministerial de Doha y la correspondiente a la aplicación del ADPIC y la salud pública, lo cierto es que no tuvieron ninguna incidencia en materia de derecho de autor.

Más recientemente, también otro acuerdo que se anunció como un instrumento para combatir la piratería y la falsificación de creaciones protegidas, el Anti-Counterfeiting Trade Agreement (АстA), ha estado en el centro del debate. Aunque ACTA fue negociado por un significativo número de países ${ }^{8} \mathrm{y}$ firmado

\footnotetext{
${ }^{4}$ Cfr. ADPIC, primer considerando.

${ }^{5}$ Cfr. PAuwelyn, Joost. "The Dog that Barked but Didn't Bite: 15 Years of Intellectual Property Disputes at the wTo", en Journal of International Dispute Settlement 1, No. 2, 2010 pp. 389-390.

${ }^{6}$ La Organización Mundial de Comercio lo califica como "el acuerdo multilateral más completo sobre propiedad intelectual". Véase la descripción del Acuerdo en el sitio Web de la omc: http://www.wto.org/spanish/tratop_s/trips_s/ intel2_s.htm.

${ }^{7}$ Cfr. Correa, Carlos. Acuerdo trips, Ciudad Argentina, Buenos Aires, 1996, p. 9. El AdPIC le otorgó una mayor significancia a la propiedad intelectual en el contexto del comercio internacional, al tiempo que lo dotó de instrumentos que permitieran exigir su cumplimiento efectivo, a diferencia de lo que venía ocurriendo con otros instrumentos internacionales que regulaban la propiedad intelectual que carecian de tales medios. Ibidem, pp. 191, 192 y 208. ${ }^{8}$ Australia, Canadá, la Unión Europea (UE), representada por su Comisión, su Presidencia y sus Estados miembros, Japón, Corea del Sur, México, Marruecos, Nueva Zelandia, Singapur, Suiza y los Estados Unidos.
} 
por ocho de ellos, ${ }^{9}$ le correspondió enfrentar la enérgica oposición de amplios sectores de la opinión pública, que consideraban ambiguo el texto del tratado y que, al quedar abierto a la interpretación, podría afectar los derechos y libertades civiles de los ciudadanos. Lo anterior supuso que el acuerdo fuera rechazado por el Parlamento Europeo en julio de $2012^{10}$ y por la Comisión Europea en diciembre del mismo año, lo que implicó que el mismo no tuviera validez en ningún país miembro de la Unión Europea. En el mismo sentido, en julio de 2012 el Senado de México rechazó la suscripción de ACTA que días antes había efectuado su embajador ante el gobierno de Japón (país depositario del tratado). También en este último caso se alegó que el Acuerdo generaba una restricción importante a los derechos fundamentales, particularmente la libertad de expresión y el debido proceso, ${ }^{11}$ aunque en el texto se habían incluido referencias expresas a la necesidad de equilibrar los derechos e intereses de titulares y usuarios, ${ }^{12}$ y a que las medidas que se tomaran en cada país debían respetar los derechos (principios) fundamentales. ${ }^{13}$

Después de las dificultades que ha enfrentado ACTA, la discusión se ha centrado en el último año en el Trans Pacific Partnership -TPP-, que, de ser concluido exitosamente, representaría por lo menos un tercio del comercio global. ${ }^{14}$ Nuevamente, el capítulo de propiedad intelectual ha atraído la atención de la comunidad académica, especialmente después de que se filtraran las propuestas de los Estados Unidos sobre este particular, además de la posición de otros países que participan en la negociación. En particular, se ha criticado la propuesta estadounidense porque establece unos altísimos estándares de protección de la propiedad intelectual, sin tener en cuenta que varios de los países negociadores tienen economías más pequeñas y con mayor necesidad de desarrollo, como el caso de Vietnam y Perú, ${ }^{15}$ lo que puede suponer que el tratado ahonde las diferencias y desequilibrios existentes entre los grandes titulares de propiedad intelectual y aquellos que requieren mayor acceso a la tecnología y el conocimiento. ${ }^{16}$

\footnotetext{
9 Estados Unidos, Australia, Canadá, Corea del Sur, Japón, Nueva Zelandia, Marruecos y Singapur.

${ }_{10}$ Comunicado del Parlamento Europeo, disponible en su página Web oficial: http://www.europarl.europa.eu/news/ es/pressroom/content/20120703/PR48247/html/El-Parlamento-Europeo-rechaza-ACTA.

"Como ocurrió en Europa, la decisión del Senado estuvo precedida de una amplia exposición mediática, principalmente en contra del tratado. Véase un resumen de los cuestionamientos al Acuerdo y la respuesta de la correspondiente autoridad gubernamental en el sitio Web del Instituto Mexicano de la Propiedad Industrial: http://www.impi. gob.mx/work/sites/IMPI/resources/LocalContent/3693/13/CuESTIONAMIENTOS_ACTA.pdf.

12 Véase el Preámbulo.

${ }^{13}$ Véase, por ejemplo, el artículo 27, Nos. 2, 3 y 4.

${ }^{14}$ Véase el sitio Web de la Oficina de Comercio de los Estados Unidos: http://www.ustr.gov/tpp.

15 Flynn, Sean M. et al. "The u.s. Proposal for an Intellectual Property Chapter in the Trans-Pacific Partnership Agreement", en American University International Law Review 28, No. 1 (2012), 105, p. 200.

16 Ibidem, pp. 119 y 120.
} 
Sin embargo, en lo que respecta a las provisiones sobre derecho de autor, en la propuesta de los Estados Unidos se encuentran también disposiciones cuyo objetivo sería lograr un mayor equilibrio entre los intereses de los titulares y de otros actores en la sociedad. En efecto, en el artículo correspondiente a limitaciones y excepciones se prevé lo siguiente:

Article QQ.G.16: Limitations and Exceptions

1. With respect to this Article [(Article 4 on copyright) and Article 5 and 6], each Party shall confine limitations or exceptions to exclusive rights to certain special cases that do not conflict with a normal exploitation of the work, performance, or phonogram, and do not unreasonably prejudice the legitimate interests of the right holder.

2. Subject to and consistent with paragraph (1), each Party shall seek to achieve an appropriate balance in providing limitations or exceptions, including those for the digital environment, giving due consideration to legitimate purposes such as, but no limited to, criticism, comment, news reporting, teaching, scholarship and research.

Como se puede observar, en el primer párrafo se propone una versión adaptada del three-step test o regla de los tres pasos, con un lenguaje que implica una restricción al establecimiento de limitaciones y excepciones en las legislaciones de los países que suscriban el tratado, elemento que ya es lugar común en todos los acuerdos internacionales en materia de derecho de autor desde que el test fuera inicialmente adoptado en la Conferencia de Estocolmo de 1967. ${ }^{17}$ No obstante esta disposición inicial, el segundo párrafo supone una nueva forma de abordar la problemática de la conjunción de intereses en derecho de autor al hacer referencia al equilibrio apropiado que debe buscarse con una política de limitaciones y excepciones; al incluir expresamente que aquellos límites también deben servir en el entorno digital y, finalmente, al utilizar un lenguaje propio de la doctrina del fair use con la que los estadounidenses han procurado alcanzar el mencionado equilibrio en su propio sistema de copyright desde el siglo XIX. ${ }^{18}$

${ }_{17}$ La regla de los tres pasos fue incorporada al texto del Convenio de Berna en el artículo 9.2, donde se reservó a las legislaciones de los paises miembros la facultad de permitir la reproducción "en determinados casos especiales, con tal que esa reproducción no atente a la explotación normal de la obra ni cause un perjuicio injustificado a los intereses legítimos del autor". Similares versiones de este test, aunque con modificaciones que ampliaron su aplicación a otros derechos y la referencia a otros titulares, han sido incluidas en el ADPIC, en los tratados OMPI de 1996, en el Tratado de Beijing de 2012 y en un número significativo de tratados bilaterales y normas comunitarias y nacionales. ${ }^{18}$ La doctrina de fair use, cuyo antecedente fue el fair abridgement inglés, comenzó a desarrollarse en la jurisprudencia estadounidense a partir de 1841 con el caso Folsom vs. Marsh. Los factores que se fueron construyendo en las decisiones judiciales fueron finalmente incluidos en el artículo (section) 107 de la Copyright Act de 1976, en donde se expresa que puede hacerse un uso leal (fair use) de una obra para propósitos tales como crítica, comentario, reporte de noticias, enseñanza (incluyendo copias múltiples para el uso en el aula de clase), erudición o investigación, sin que tal uso implique la infracción al copyright. Para determinar si un uso en particular es justo (fair) se deben evaluar los siguientes factores: 1) el propósito y el carácter del uso, incluyendo si tal uso es de naturaleza comercial o si es 
Este nuevo enfoque ha sido reconocido incluso por tradicionales críticos de las políticas internacionales de propiedad intelectual de los Estados Unidos, indicando que con ello se estaría evidenciando una mayor apertura y flexibilidad de la principal economía del mundo en los temas de derecho de autor. ${ }^{19}$

Un paso en la misma dirección se hizo presente en las negociaciones del tratado internacional sobre limitaciones y excepciones a favor de personas con discapacidad visual -en el marco de la agenda para el desarrollo de la oMPIque, al suscribirse en Marrakech (Marruecos) en junio de 2013, se convirtió en el primer acuerdo internacional dirigido exclusivamente a la consagración de excepciones y limitaciones al derecho de autor, lo que supuso una variación en la perspectiva tradicionalmente enfocada en los derechos de los titulares. En esta línea, en el proyecto de instrumento que se negoció en la sesiones previas a la de Marrakech ${ }^{20}$ se incluyeron un considerando en el que se reconoció la importancia y "flexibilidad" de los criterios del three-step test ${ }^{21}$ y un artículo dedicado a la interpretación del test en el que se estipuló que deben tenerse en cuenta los intereses legítimos de terceros, incluyendo derechos humanos, libertades fundamentales, intereses relacionados con la competencia y otros intereses públicos. ${ }^{22}$ Aunque este último artículo fue suprimido en la versión final del tratado, lo cierto es que en los primeros considerandos del texto final se resaltó la importancia

para propósitos educativos sin ánimo de lucro; 2) la naturaleza de la obra protegida; 3) la cantidad y sustancialidad de la porción usada respecto de la obra protegida en su totalidad, y 4) el efecto del uso sobre el mercado potencial o sobre el valor de la obra protegida. Una explicación más detallada del fair use y de la interpretación de sus criterios puede verse en Córdoba Marentes, JuAn F. "El fin no justifica la excepción: propiedad intelectual, educación y el fair use estadounidense", en Boletín Mexicano de Derecho de Autor, No. 134 (2012), 437, passim.

${ }^{19}$ Cfr. Flynn, Sean M. et al. "The u.s. Proposal for an Intellectual Property Chapter in the Trans-Pacific Partnership Agreement", op. cit., p. 143. Sin embargo, algunos siguen considerando que el encabezado de este segundo párrafo ("sujeto y consistente con lo dispuesto en el párrafo 1") no haría sino convertir el tpp en un instrumento más restrictivo que el ADPIC o el Tratado ompI de Derecho de Autor. Véase la opinión de James Love en Knowledge Ecology International, disponible en: http://keionline.org/node/1516.

20 Proyecto de texto de tratado o instrumento internacional relativo a las limitaciones y excepciones para personas con discapacidad visual/personas con dificultad para acceder al texto impreso, VIP/DC/3, 5 de febrero de 2013, disponible en el sitio Web de la Organización Mundial de Propiedad Intelectual: http://www.wipo.int/edocs/mdocs/ diplconf/es/vip_dc/vip_dc_3.pdf.

21 "(Décimo) Reafirmando las obligaciones contraídas por los Estados miembros en virtud de tratados internacionales vigentes en materia de protección del derecho de autor, así como la importancia y la flexibilidad de los tres criterios que condicionan el establecimiento de limitaciones y excepciones estipulados en el párrafo 2 del artículo 9 del Convenio de Berna y en otros instrumentos internacionales (...)". Esta redacción del considerando fue propuesta por México. Véase el Documento ompI SccR/24/9, del 26 de julio de 2012.

22 "Artículo I. Interpretación de la regla de los tres pasos [La regla de los tres pasos deberá interpretarse respetando los intereses legítimos de terceros, con inclusión de: a) los intereses derivados de los derechos humanos y las libertades fundamentales; b) los intereses relacionados con la competencia, en particular, los relativos a los mercados secundarios; y c) otros intereses públicos, en particular, los relativos al progreso científico y al desarrollo cultural, educativo, social y económico]". Sin embargo, este artículo ha sido objeto de una álgida discusión en las últimas reuniones preparatorias y muy probablemente será eliminado. 
de ciertos derechos humanos y libertades personales que deben ser protegidos en un sistema de protección del derecho de autor. ${ }^{23}$

Indudablemente, resulta muy positiva esta tendencia de equilibrar los derechos humanos con otros derechos e intereses que se entremezclan en los procesos integracionistas porque, como se explicará en este trabajo, los instrumentos que fomentan el comercio internacional deben tener por propósito principal la consecución del bien común en el contexto de la cooperación económica. Y siendo que, precisamente, los derechos humanos son parte fundamental del contenido del bien común, los sistemas de derecho de autor están llamados a materializar fórmulas que efectivamente consigan tan anhelado equilibrio. La figura de las limitaciones y excepciones al derecho de autor se postula como una de estas fórmulas conciliadoras entre el régimen autoralista y los derechos humanos, pero debido a los presupuestos iusfilosóficos que hasta ahora han sustentado estas nociones, en la práctica ha sido imposible conseguir su verdadera armonización. Los procesos de integración económica son una clara muestra de las luchas, en este sentido, "entre bandos opuestos". Como alternativa para mejorar este panorama, en esta investigación se propone, en primer lugar, una reconsideración de la naturaleza de las limitaciones y excepciones al derecho de autor fundadas en una visión realista de este derecho y, en segundo lugar, la reivindicación de la noción de bien común.

\section{El lugar de las excepciones y limitaciones en el estatuto de protección al derecho de autor}
A) El derecho de autor como derecho de propiedad: la exaltación de un derecho subjetivo absoluto

Paradójicamente, a los absolutismos monárquicos que las revoluciones pretendieron eliminar en la segunda parte del siglo xvill se respondió con otra clase de absolutismo, esta vez de raigambre jurídica e individualista. En efecto, en la medida en que los monarcas iban siendo destronados, se tendió a entronizar al individuo y a construir una estructura jurídica en la que predominaban sus derechos y se minimizaban sus deberes. ${ }^{24}$ El campo de la protección de las creaciones intelectuales no fue la excepción a esta tendencia, y así como se re-

\footnotetext{
${ }^{23}$ Véanse, por ejemplo, considerandos primero y segundo en la versión final del tratado, disponible en el sitio Web de la ompl: http://www.wipo.int/treaties/es/text.jsp?file_id=302979.

${ }^{24}$ Sobre este droit intermédiare que se dio entre la Revolución Francesa y la llegada al poder de Napoleón Bonaparte, ZWEIGerT y Kötz comentan que se extirparon viejas instituciones políticas en muy corto plazo y que, para conseguir
} 
clamó igualdad, libertad y fraternidad, el derecho del autor sobre sus obras fue equiparado al de propiedad privada, piedra angular del nuevo sistema político y económico. Y si el derecho a la propiedad material ya era considerado como una facultad fundamental, se hicieron importantes esfuerzos para sacralizar aún más el derecho del hombre sobre las producciones de su intelecto. Esto se demuestra, por ejemplo, con los decretos de 1791 y 1793 -normas que configuraron primitivamente el sistema de droit d'auteur en Francia- y la forma como ellos fueron presentados y desarrollados por los correspondientes dirigentes y juristas, quienes se empeñaron en calificar el derecho del creador sobre sus obras como "sagrado" e "indiscutible". ${ }^{25}$ Retomando las ideas que sobre la propiedad estaban en boga para la época, se adaptó este concepto jurídico a la facultad que se podía ejercer sobre las creaciones del espíritu, en cuanto extensión de la personalidad del autor, inviolable como era su individualidad. Los planteamientos legales y políticos iniciales fueron posteriormente validados y extendidos por la filosofía alemana y la jurisprudencia francesa y alemana del siglo $x \mathrm{xx},{ }^{26}$ las que a su vez influyeron en la actualización normativa, incluyendo la regulación internacional en el Convenio de Berna y los ordenamientos nacionales sobre propiedad intelectual.

En los antecedentes jurídicos mencionados, el derecho de autor fue adquiriendo los perfiles que caracterizaban a la propiedad material y, además, otros propios de su naturaleza intelectual y “espiritual”. Dentro de estas peculiaridades, el carácter absoluto de los derechos reales se atribuyó igualmente al derecho de autor, en tanto derecho subjetivo, en sus aspectos interno y externo. Así, según el aspecto interno del derecho de autor, se entendía que éste podía ejercer, directa y autónomamente, un gobierno sobre la creación intelectual, como cualquier propietario lo haría sobre la cosa objeto de dominio, es decir, ejerciendo un poder absoluto sobre su bien, satisfaciendo sus necesidades e intereses sin requerir, y más bien excluyendo, la intermediación de un tercero. ${ }^{27}$ Por otro lado, de acuerdo con el aspecto externo del derecho, era posible atribuir la carga de su respeto al resto de la comunidad (al denominado sujeto universal), impidien-

este objetivo, la legislación durante este periodo fue extremadamente individualista. ZWEIGERT, KonRAD y KöTZ, HeIN. Introducción al derecho comparado, trad. de Tony Weir, Oxford, México, 1998, pp. 80 y 81.

${ }_{25}$ Para ello, se suelen citar las palabras de Le ChaPelieR, replicadas por LAKANAL: "[...] la plus sacrée et la plus légitime, la plus inattaquable et la plus personnelle de toutes les propriétés". Citado por KeREVER, André. "Révolution Française et droit d'auteur", en Revue Internationale du Droit d'Auteur [RIDA], 141 (1989), p. 3.

${ }^{26}$ Véase, por ejemplo, DAviES, GiLıan. Copyright and the Public Interest, Thomson Sweet \& Maxwell, Londres, 2002, pp. $144,145,148-150$ y $179-187$.

${ }_{27}$ Una de las características con las que se quiso asimilar la propiedad intelectual con la propiedad física es la referida a la "perpetuidad" del derecho sobre la creación, llegando incluso a calificar de "comunistas" las posturas que se oponían a dicho carácter perpetuo. Sobre el particular véase el recuento que se hace de la discusión en PABón, JHONNY Antonio. De los privilegios a la propiedad intelectual, Universidad Externado de Colombia, Bogotá, 2010, pp. 225-228. 
do que cualquier tercero, en principio indeterminado, perturbara las facultades exclusivas del creador sobre su obra. ${ }^{28}$

\section{в) El derecho de autor desde una perspectiva "moderna" de los derechos humanos}

A la nota de absolutidad propia de los derechos reales se sumó posteriormente una desafortunada lectura individualista de los derechos humanos, cuando el derecho de autor fue elevado a tal categoría. La incursión de la noción de derechos humanos en la modernidad se sustentó en buena parte sobre los mismos pilares denunciados líneas atrás: la entronización del individuo y, con él, de la libertad personal, como centro del ordenamiento jurídico.

Así, como fueran formulados en su origen (moderno), los derechos humanos son una reivindicación jurídica de la libertad natural, concebida utópicamente en términos absolutos pero que, frente a la realidad humana de necesitarse unos a otros, adquieren un matiz: los derechos humanos son la concreción jurídica de esas libertades fundamentales concebidas en la máxima amplitud posible y tan solo limitadas por el alcance del ámbito de libertad de los demás. ${ }^{29}$ Así las cosas, la figura de los derechos humanos como expresión histórica moderna se funda sobre una antropología típica de la época que rompe con el pasado y se sustenta, entre otras, en las siguientes notas representativas de esa sociedad: la primacía de la autonomía personal, el instanteísmo como posición del hombre sin compromiso con el tiempo, el contractualismo como explicación de la organización política, y el mercado como expresión de la economía. ${ }^{30}$

$Y$ aunque es cierto que una de las notas características de los derechos humanos es su eficacia frente a todos (erga omnes) -esto es, exigibles tanto frente al Estado como frente a terceros-, ${ }^{31}$ de esta condición no tiene por qué derivarse

\footnotetext{
${ }^{28}$ Cfr. Baylos Corroza, Hermenegildo. Tratado de derecho industrial, 2a. ed., Civitas, Madrid, 1993, p. 503. El autor no sólo reitera la posición según la cual el derecho de los creadores es un derecho subjetivo, de carácter absoluto, sino que además lo tipifica como uno del cual proviene poder jurídico remisivo, con unas notas especiales, ya que no se remite a la creación espiritual exteriorizada sino a todo el haz de prerrogativas (de facere) que pueden ser ejercidas respecto del objeto del derecho.

${ }^{29}$ Esta mirada de los derechos humanos, infortunadamente todavía muy arraigada en algunos sectores, explica buena parte de las tensiones que se generan en este ámbito: "Si la felicidad consiste en la libertad por la libertad misma, y si el despliegue de la libertad personal tiene como único impedimento las libertades de los demás [...] el único obstáculo real para la realización personal son los restantes hombres". CIANCIARDO, JuAn. El conflictivismo en los derechos fundamentales, Eunsa, Pamplona, 2000, p. 160.

30 Una ampliación de estas notas características del pensamiento moderno y su vinculación con el origen de los derechos humanos puede verse en el capítulo dos de la obra de J. CIANCIARDo atrás mencionada.

${ }^{31}$ Parafraseando la doctrina del Drittwirkung del Tribunal Constitucional alemán, puede afirmarse que los derechos fundamentales tienen eficacia frente a particulares y no sólo en las relaciones entre el Estado y los individuos. Al
} 
una suerte de antagonismo entre el titular de un derecho y la sociedad a la que éste pertenece. Este error común -fruto del subjetivismo pregonado por las doctrinas liberales modernas- explica una visión muy difundida de los derechos humanos, que los concibe como escudos de defensa de una individualidad exacerbada; por tanto, opuestos unos a otros o en permanente conflicto. ${ }^{32}$ Esta mirada de los derechos humanos influyó también sobre la concepción del derecho de autor. Visto así, bajo la protección que otorga ese lenguaje de los derechos humanos, el derecho de autor consigue crear una especie de barrera que protege al titular de las obras de ser "perturbado" en el disfrute de sus derechos, asentándose su carácter individualista y absoluto.

En la práctica, estas dos notas condujeron a un paradigma jurídico: la imposibilidad de que las creaciones protegidas por el derecho de autor fueran disfrutadas por los terceros que no hubieran sido debidamente autorizados por los titulares para ejercer ciertos usos, esos sí limitados. De esa forma, la absolutidad, entendida como titularidad directa y prevalente frente al resto de la comunidad, se fue transformando en una característica excluyente de todo interés distinto de aquel del autor o el titular.

A pesar de estos desarrollos, principalmente en el derecho francés, en los regímenes del Common Law y en el derecho alemán se dieron los primeros pasos para limitar los derechos exclusivos de los autores y titulares. En el caso anglosajón, las teorías utilitaristas influyeron en la configuración de los sistemas protectores de propiedad intelectual, donde, además de garantizar los derechos de los creadores, se previeron mecanismos que permitían a los terceros utilizar las creaciones de otros, en la medida en que con ello se generaran mayores beneficios sociales. Este fue el caso del fair abridgement, el fair dealing y, como una evolución estadounidense de las anteriores instituciones, el fair use. De igual forma, en el derecho de autor alemán se acudió al concepto de interés público para justificar la concesión de limitaciones a los derechos exclusivos de explotación en su ordenamiento interno y para abogar por su introducción en la normativa internacional. ${ }^{33}$

respecto puede verse De Domingo, Tomás. "El problema de la drittwirkung de los derechos fundamentales: una aproximación desde la filosofía del derecho", en Derechos y Libertades 7, No. 11 (2002), pp. 251-289.

32 Sobre el marco epistemológico del fenómeno del conflictivismo en los derechos fundamentales pueden verse las siguientes obras: Cianciardo, Juan. El conflictivismo en los derechos fundamentales, cit., passim; Serna, Pedro y Toller, Fernando. La interpretación constitucional de los derechos fundamentales: una alternativa a los conflictos de derechos, La Ley, Buenos Aires, 2000, passim; Toller, Fernando. "La resolución de conflictos entre derechos fundamentales", en Ferrer Mac-Gregor, Eduardo (ed.). Interpretación constitucional, Porrúa, México, 2005, p. 1199, passim. ${ }^{33}$ Algunos autores van más lejos, al considerar al derecho de autor como un régimen precursor en la compatibilización de los intereses privados con la función social: "La propiedad intelectual representa desde sus inicios, cuando no había ni los más leves atisbos de la función social de la propiedad, ni de su subordinación al interés común, la más evidente manifestación de su función y sometimiento a los intereses sociales". Rodriguez TAPIA, José Miguel y Bondia 
El problema de estas perspectivas es que siguen la misma lógica moderna que se ha denunciado (el individualismo y el liberalismo) y, por tanto, la visión conflictivista de los derechos - para el caso, el derecho de autor en oposición a pretendidas reivindicaciones colectivas fundadas sobre alegados derechos humanos- alcanza también a los procesos de integración: ya no individuos, sino sociedades nacionales que se enfrentan cada cual para lograr la mayor ganancia propia (esto es lo que podríamos entender como procesos integracionistas basados en posiciones de poder), sin consideración a un referente mayor que justifica las alianzas interestatales: el bien común.

\section{c) Una nueva visión del derecho de autor, sus excepciones y limitaciones}

Comprender el lugar que ocupan las limitaciones y excepciones en el régimen del derecho de autor supone el paso previo de aproximarse a la naturaleza de este derecho y su sustento sobre la realidad. Como alternativa a las propuestas de los dos apartados anteriores, podemos afirmar sucintamente que el derecho de autor goza de naturaleza compuesta: es en parte natural y en parte positivo. Este argumento se explica sobre la base que ofrecen las nociones de fundamento del derecho, título jurídico y medida. ${ }^{34}$ Para el caso, el fundamento del derecho de autor se puede ubicar en la naturaleza humana debido a su relación directa con algunos bienes humanos básicos (como el conocimiento, la experiencia estética, el trabajo y el juego $)^{35}$ y ciertas inclinaciones propias de la persona (por ejemplo,

Román, Fernando. Comentarios a la Ley de Propiedad Intelectual, Civitas, Madrid, 1997, pp. 164 y 165; Bécourt, por su parte, considera que en la Revolución Francesa, aunque se preconizaban la libertad y la propiedad como derechos naturales, se entendía que su ejercicio debía sujetarse a la función social que les correspondía. Bécourt, Daniel. "La Revolución Francesa y el derecho de autor: por un nuevo universalismo", en Boletín de Derecho de Autor - Unesco XXIV, No. 4 (1990) 4, p. 5.

${ }^{34}$ Estas nociones traídas de la filosofía aristotélico-tomista son muy útiles para comprender la existencia y contenido de los derechos. Para un análisis de estos presupuestos véase HeRVADA, JAVIER. Introducción crítica al derecho natural, Temis-Universidad de La Sabana, Bogotá, 2000, pp. 49-54 y 65-67.

${ }_{35}$ Dado que en este trabajo se continuará haciendo referencia a los "bienes humanos básicos" o "valores básicos", es importante aclarar lo que significa este concepto que, en la filosofia moderna, es principalmente desarrollado por FinnIs. La explicación central se puede encontrar en los capítulos III, IV y v de Ley natural y derechos naturales. Por ahora, para los propósitos de esta inicial aproximación, basta citar el "Estudio preliminar" que hace OrRego sobre la obra de Finnis en su traducción al castellano: "Las formas básicas del bien captadas por el entendimiento práctico son lo que es bueno para los seres humanos con la naturaleza que tienen [...] Finnis sostiene que los primeros principios de la razón práctica -también el primerísimo en que todos los demás se fundan: bonum est faciendum et prosequendum et malum vitandum - y los correspondientes bienes humanos básicos son evidentes de suyo (per se nota) y no requieren demostración, aunque si experiencia, pues no son innatos. Los bienes o valores básicos, a fuer de evidentes son igualmente primarios e inconmensurables entre sí, es decir, ninguno es más básico que los otros y no existe una escala uniforme que permita medir los valores básicos en términos de algún bien todavía más básico con el fin de subordinar o sacrificar unos valores en aras de los mayores". OrRego, Cristóbal. "Estudio preliminar", en Finnis, John. Ley natural y derechos naturales, trad. de Cristóbal Orrego, Abeledo-Perrot, Buenos Aires, 2000, pp. 18-20. 
la tendencia a la comunicación de las ideas, al diálogo y a la transformación del mundo a través del conocimiento), por lo que puede decirse que el fundamento del derecho de autor es de orden natural y no meramente convencional o acordado en el marco social. Desde esta óptica, habría razones para catalogarlo como derecho humano. Por otro lado, debido al carácter y función de este derecho, parece claro que su título es positivo, puesto que sólo puede ser atribuido en un entorno político mediante acuerdos y determinaciones de derecho positivo que en todo caso se asientan sobre una realidad: el objeto sobre el que recae el derecho de autor. ${ }^{36}$ Ahora bien, sobre la base que ofrece esa realidad cabe un amplio margen de discrecionalidad a los Estados y a la misma comunidad internacional para definir la medida del derecho de autor, esto es, el alcance de protección legal que se concede al derecho de autor en un contexto histórico determinado.

El derecho de autor es, además, un derecho subjetivo que faculta a su titular a ejercer unas atribuciones exclusivas similares a las de la propiedad y que, por lo mismo, es beneficiario y tributario del acervo común de la humanidad, cuya existencia es más clara en relación con el conocimiento, el arte, la ciencia y la cultura. La principal consecuencia de esta relación con el acervo común es que, aunque es de justicia reconocer al autor una especie de propiedad como recompensa por su producción intelectual, ese dominio sobre la obra debe contribuir al bien común del que el mismo autor obtuvo provecho. Esta mirada abona un terreno hasta ahora poco explorado en la materia y que, sin embargo, resulta sumamente ventajosa para el planteamiento de escenarios de integración.

De las anteriores formulaciones se puede concluir que el derecho de autor, como todo derecho -en cuanto reflejo de uno o varios bienes básicos-, tiene unos límites internos impuestos por su misma naturaleza y unos condicionamientos externos definidos por la noción de bien común. De esto se colige que los derechos de los autores y los titulares subsecuentes, si bien tienen fundamento natural y se encuentran sustentados en bienes humanos básicos, no pueden considerarse absolutos, ${ }^{37}$ lo que es lo mismo que decir que las limitaciones no son un concepto sobrepuesto.

\footnotetext{
${ }^{36}$ La perspectiva realista por la que se apela, plantea como punto de partida la posibilidad de la razón (del legislador o del juez) de determinar el contenido del derecho de autor conforme pautas que ofrece la realidad objetiva, para excluir decisiones (legislativas o judiciales) arbitrarias. Asi, por ejemplo, el objeto del derecho de autor se define en función de aquella cosa que en justicia se debe al creador de la obra, esto es, la forma de expresión de las ideas en el marco de una cultura, mas no las ideas por sí mismas que no son objeto de apropiación exclusiva por esa cultura ni ese autor.

37 Véase, entre otros, Antequera Parilu, Ricardo. "Los límites del derecho subjetivo y del derecho de autor", en Rogel VIDE, CARlos (ed.). Los límites del derecho de autor, Reus, Madrid, 2006, pp. 8 y 9.
} 
En este punto cabe aclarar que los términos "limitaciones" y "excepciones" se utilizan indistintamente en los instrumentos internacionales y las leyes nacionales, ${ }^{38}$ a pesar de que los doctrinantes sobre la materia insisten en diferenciarlos y circunscribirlos a unas realidades precisas. ${ }^{39}$ Ahora bien, más allá de las disquisiciones doctrinales, lo que interesa subrayar para los propósitos del presente estudio es que "limitaciones" o "excepciones" son condiciones connaturales al derecho de autor, puesto que, como ha sido sustentado, éste no es ni un derecho de propiedad absoluto ni un derecho humano del tipo libertad fundamental irrestricta, que en verdad no existe.

En la práctica, esos límites deben ser determinados o especificados en aras de proteger el derecho "limitado" - en este caso, el del autor- y otros bienes relacionados. ${ }^{40}$ De ahí que no se debe confundir la exclusividad ${ }^{41}$ propia del

\footnotetext{
38 Por ejemplo, tanto el artículo 13 del ADPIC como el artículo 10 del TODA (Tratado ompI de Derecho de Autor), al consagrar sus respectivas versiones del three-step test, se refieren indistintamente a limitaciones y/o excepciones. ${ }^{39}$ Algunos han sostenido, por ejemplo, que las "limitaciones" hacen referencia a aquellos usos que no requieren de una autorización del titular pero sí una compensación económica equitativa, como en el caso de las licencias obligatorias, mientras que las "excepciones" atañen a los usos que se hacen sin necesidad de autorización y sin pago al titular (entre otros, FICSOR, MIJÁLY. The Law of Copyright and the Internet - The 1996 wIPO Treaties, their Interpretation and Implementation, Oxford University Press, Oxford, 2002, p. 257; Vázouez, Victor. "Perspectivas de futuro en torno a los limites del derecho de autor. Las tendencias internacionales y la posición de la OMPI", en RogeL VIDE, CARLos (ed.). Los límites del derecho de autor, Reus, Madrid, 2006, p. 296; González de Alaiza Cardona, José Javier. La copia privada: sus fundamentos y su tratamiento en el entorno digital, Comares, Granada, 2008, p. 103, en donde el autor manifiesta que éste es el uso corriente que le da la doctrina). Otros consideran que tanto las limitaciones como las excepciones se refieren siempre a la posibilidad de usar libre y gratuitamente la obra, mientras que las licencias no voluntarias u obligatorias, que exigen el pago de una remuneración equitativa, constituirian una categoría aparte (cfr. RodRiguez Moreno, Sofia. La era digital y las excepciones y limitaciones al derecho de autor, Universidad Externado de Colombia, Bogotá, 2004, p. 66. Por otro lado, Rodriguez Tapia y Bondia Román prefieren referirse a "supuestos de libre utilización de las obras", en el entendido de que fuera de estos supuestos las amplias facultades de los titulares no se ven afectadas, manteniéndose el monopolio que existiría respecto de la obra. Rodriguez Tapia, José Miguel y Bondia Román, Fernando. Comentarios a la Ley de Propiedad Intelectual, cit., p. 164). Finalmente, para algunos la distinción semántica obedece a la naturaleza misma de los derechos protegidos, que variaría según se trate del régimen basado en el sistema de derecho civil o en aquel sustentado en el Common Law (en este sentido se pronuncian LucAs y LucAs, refiriéndose particularmente a la forma como está regulado el tema en el derecho francés. LUCAS, AndRÉ y LUCAS, HenRI-JACQues. Traité de la Propriété Litteraire et Artistique, 3a. ed., LexisNexis, Paris, 2006, p. 258). También es verdad que acorde con las ideas utilitaristas que desde sus inicios fundamentaron el sistema de copyright, los beneficios que recibe el titular de la creación deben compaginarse con los beneficios sociales derivados de su explotación y uso, por lo que, en aras de lograr la máxima utilidad, privada y pública, se justifica "limitar" los estímulos otorgados a los titulares de derechos. Estas limitaciones harían parte de la esencia del sistema protector y no compartiría la designación de excepcional que se predica respecto de los usos excluidos en el sistema de derecho civil (cfr. Guibault, Lucie M. Copyright Limitations and Contracts - An Analysis of the Contractuall Overridability of Limitations on Copyright, Kluwer, La Haya-Londres-Boston, 2002, pp. 17-20; SenfleBen, Martin. Copyright, Limitations and the Three-Step Test: An Analysis of the Three-Step Test in International and EC Copyright Law, Kluwer Law International, La Haya, 2004, p. 22). Aunque esta última posición posee elementos que la hacen más consistente juridicamente, lo cierto es que, en general, la distinción de términos no ha tenido mayor incidencia en las discusiones sobre la naturaleza de las excepciones, por lo que se mantiene en este estudio el uso indiferenciado de los dos términos.

${ }^{40}$ Cfr. FinnIs, JoHn. Ley natural y derechos naturales, cit., p. 248.

${ }^{41}$ Sin embargo, el término "exclusividad" también transmite la idea de que algo pertenece a un individuo que, consecuentemente, puede "excluir" a los demás de su disfrute.
} 
derecho del autor con la absolutidad, como sinónimo de ilimitación. ${ }^{42}$ Negar la posibilidad de limitación implica dejar de lado la naturaleza del derecho del autor que supone su contribución al bien común, facilitando el disfrute de bienes humanos básicos como el conocimiento, la comunicación, la experiencia estética y el trabajo. De la misma manera que el autor, además de su talento y esfuerzo, ha obtenido fruto del acervo común del que participa, está también llamado a contribuir con su creación a la optimización de este activo en beneficio de toda la humanidad, generándose una retroalimentación mutua entre creador y sociedad..$^{43}$ En otras palabras, las limitaciones a los derechos del autor que permitan lograr esta interacción deben ser consideradas parte esencial del sistema autoralista y no simples concesiones toleradas y extrañas a una política de protección de la propiedad intelectual. ${ }^{44}$

\section{La reivindicación de la noción de bien común: una alternativa para conciliar el derecho de autor y los derechos humanos}

De igual forma que toda persona necesita de los demás para lograr sus propios fines, ya que no se basta a sí misma, ${ }^{45}$ el derecho de autor, como toda institución jurídica, sólo puede existir y entenderse en un contexto social. En consecuencia, aun cuando el régimen autoralista se centre en la persona del creador -y del titular derivado o subsecuente-, su alcance no se puede limitar a la protección de unos bienes eminentemente individuales - derecho patrimonial y moral-, sino que, además, debe contemplar la manera como esos bienes originan relaciones jurídicas con otros actores sociales que, aunque inicialmente deudores, también pueden llegar a ser acreedores en estos vínculos de justicia. Y así como toda sociedad tiene por fin la consecución del bien común mediante la satisfacción ordenada de distintas clases de bienes, el derecho de autor, en cuanto inscrito en la sociedad, debe contribuir a ese bien común mediante la adecuada protección y promoción de los valores fundamentales sobre los que se construye, y los bienes humanos básicos por los que propende.

\footnotetext{
42 Véase el prólogo de E. Rengifo Garcia en Rodriguez Moreno, Sofia. La era digital y las excepciones y limitaciones al derecho de autor, cit., p. 20.

${ }^{43}$ Cfr. Antequera Parilu, Ricardo. Estudios de derecho de autor y derechos afines, Madrid, Reus, 2007, pp. 24-30.

${ }^{44}$ Guibault, LuCie M. "Naturaleza y alcance de las limitaciones y excepciones al derecho de autor y los derechos conexos en relación con las misiones de interés general de la transmisión del conocimiento: sus perspectivas de adaptación al entorno digital", en Boletín de Derecho de Autor - Unesco, octubre-noviembre de 2003, pp. 2 y 3; SIRIneLLI, PIerRe. Excepciones y limitaciones al derecho de autor y los derechos conexos (Estudio), ompI, Ginebra, 1999, p. 1. ${ }^{45}$ Cfr. VIGo, Rodolfo L. Las causas del derecho, Abeledo-Perrot, Buenos Aires, 1983, p. 166. El autor sustenta esta afirmación en el principio aristotélico del hombre como animal social o político y en la expresión de TomÁs DE AquINo de que "el hombre necesita que le ayuden los demás para conseguir su propio fin".
} 


\section{A) Introducción del concepto de bien común: el paulatino abandono de las categorias individualistas}

La cuestión planteada ha sido estudiada en el último medio siglo bajo distintas denominaciones, principalmente la de "interés público" ${ }^{46}$ y ha repercutido en el debate sobre los límites que le corresponden a los derechos de los autores y de los titulares subsecuentes. Sin embargo, el concepto de interés público pareciera ser insuficiente ${ }^{47}$ en la medida que se le identifique con interés general y, por tanto, opuesto a los intereses individuales que debería abarcar. En efecto, el concepto de interés general se refiere más al interés de la colectividad objetivamente considerada, el cual se estima que prevalece sobre los derechos individuales que lo componen, que a su vez pueden ser sacrificados para proteger aquél. Un concepto así difiere del de bien común, porque este último supone la conjunción de los intereses o bienes de todos y cada uno de los miembros de la sociedad, encaminados todos ellos hacia un fin que les es común.

Para esta visión del bien común que se defiende aquí, el fin compartido por los miembros de la comunidad (fin común) no excluye los bienes particulares de los individuos que la integran, como sucede con el concepto de interés general, que usualmente se encuentra en tensión frente al de interés particular. Por el contrario, la noción de bien común exige el bien particular de todos los integrantes de la comunidad -en el sentido de realización personal- ${ }^{48}$ pero no es que se calcule sobre bases estadísticas o utilitarias. A decir verdad, el bien común no es el "mayor bien del mayor número", sino un bien que a la vez que abarca a todos los miembros de la sociedad, supera las meras realizaciones individuales y se sitúa como

[...] el conjunto de condiciones materiales y espirituales, de muy variado contenido (políticas, sociales, económicas, culturales y educativas, urbanísticas y ambientales, etcétera), que favorecen el normal y pleno desarrollo de la persona humana y de los grupos que integran la sociedad política y que han de ser creadas por y para todos

${ }^{46}$ Un completo estudio sobre la estrecha relación entre el derecho de autor y el interés público se puede encontrar en la obra de Davies, GiLlan. Copyright and the Public Interest, cit., passim.

${ }^{47}$ Vázouez utiliza los términos "interés legítimo" e "interés público", pero afirma que esas nociones están estrechamente relacionadas con la politica nacional y la "idiosincrasia local", por lo que lo que se considera interés público en un país puede no serlo en otro. Vázouez, Victor. Perspectivas de futuro en torno a los límites del derecho de autor. Las tendencias internacionales y la posición de la ompl, cit., pp. 295-308.

${ }^{48}$ Esta visión coincide con la teoría finniseana del personal flourishment, como sustrato de la noción de bien común. Para este autor, el bien común es un conjunto de condiciones materiales y de otro tipo, dentro de las cuales se cuentan los derechos humanos que tiendan a favorecer y fomentar ese desarrollo personal de cada individuo que compone la comunidad. Cfr. FinNIS, JoHn. Ley natural y derechos naturales, cit., pp. 177-185. 
y cada uno de sus integrantes, bajo el lúcido y limitado gobierno de la autoridad pública. $^{49}$

En líneas similares, la Corte Interamericana -máximo tribunal del continente americano en materia de derechos humanos- ha afirmado que:

Es posible entender el bien común, dentro del contexto de la Convención, como un concepto referente a las condiciones de la vida social que permiten a los integrantes de la sociedad alcanzar el mayor grado de desarrollo personal y la mayor vigencia de los valores democráticos. En tal sentido, puede considerarse como un imperativo del bien común la organización de la vida social en forma que se fortalezca el funcionamiento de las instituciones democráticas y se preserve y promueva la plena realización de los derechos de la persona humana. ${ }^{50}$

Como puede observarse, una mirada de conjunto de las definiciones referidas permite plantear el bien común como un centro de armonización de intereses particulares y colectivos -en contraste con figuras que se estancan en una visión conflictivista-, producto de la participación articulada de todos los actores sociales (individuos, familias, asociaciones intermedias, empresas, Estados, organizaciones intergubernamentales, comunidad internacional...) con miras a contribuir al más alto desarrollo personal y comunitario. Así queda claro que se trata de una figura dinámica que está llamada a concretarse en el tiempo, atendiendo a las circunstancias particulares de cada sociedad pero, a la vez, fundada sobre el valor inmutable de la dignidad humana como criterio central para la configuración de aquellas condiciones esenciales que le permitirán el pleno desarrollo a las personas en el contexto social al que pertenecen. Dicho de otra manera, el bien común es esencialmente un orden dinámico, en el que cada integrante debe contar con los medios necesarios para satisfacer sus propios fines

\footnotetext{
49 Cfr. Santiago, Alfonso. En las fronteras entre el derecho constitucional y la filosofía del derecho, Marcial Pons, Madrid, 2010, p. 91. La propuesta de MariTAIn en este mismo sentido es todavia más específica. Para este autor, esta misma idea de conjunto está compuesta tanto por las condiciones sociales necesarias para el desarrollo de los fines de la comunidad, como por "todo lo que supone conciencia cívica, de las virtudes políticas y del sentido del derecho y de la libertad, y de todo lo que hay de actividad, de prosperidad material y de tesoros espirituales, de sabiduría tradicional inconscientemente vivida, de rectitud moral, de justicia, de amistad, de felicidad, de virtud y de heroísmo, en la vida individual de los miembros de la comunidad, en cuanto que todo esto es comunicable, y se distribuye y es participado, en cierta medida, por cada uno de los individuos, ayudándoles así a perfeccionar su vida y su libertad de persona". Argandoña, Antonio. "El bien común", documento de investigación DI-937, IESE Business School, julio de 2011. 50 Corte Interamericana de Derechos Humanos. La Colegiación Obligatoria de Periodistas (Arts. 13 y 29 Convención Americana sobre Derechos Humanos), Opinión Consultiva oc-5/85 del 13 de noviembre de 1985, Serie A, No. 5, párr. 66. En el párrafo anterior la Corte había anotado: "es válido sostener, en general, que el ejercicio de los derechos garantizados por la Convención debe armonizarse con el bien común".
} 
y, al mismo tiempo, contribuir con su esfuerzo y participar de las conquistas de la colaboración común. ${ }^{51}$

Visto de este modo, se pueden plantear algunas hipótesis para el campo del derecho de autor: a) en primer lugar, la reivindicación del concepto de bien común en nuestros días supone un replanteamiento del individualismo liberal en la base de la concepción "moderna" del derecho de autor; b) consecuentes con el punto anterior, en segundo lugar, puede afirmarse que superado el sesgo individualista, el derecho de autor no sólo deja de enfrentarse a otros derechos (incluso humanos), sino que consigue armonizarse con ellos, y c) de las anteriores premisas puede concluirse que el derecho de autor, replanteado a la luz del concepto de bien común, puede convertirse en un elemento jurídico que facilite los procesos de integración comunitaria, puesto que distinto a ser un motivo de arraigar tensiones y luchas de poder entre las naciones, se convierte en un motor que impulsa relaciones internacionales convergentes (en función del bien común). Los argumentos para desarrollar estas hipótesis se expondrán en lo que sigue del documento.

\section{B) El derecho de autor y sus límites en el marco del bien común}

El concepto de bien común es fundamental a la hora de determinar los límites y las exigencias a las que se encuentran sujetos los derechos e intereses de los distintos actores que confluyen en el derecho de autor: autores, industria y usuarios. De hecho, varios de ellos alegan razones superiores, de interés público o de bien común, cuando se trata de defender su posición en el entramado de relaciones jurídicas que se gestan con ocasión de la explotación y uso de las obras protegidas. Por lo anterior, como se ha afirmado, es necesario ahondar en el concepto de bien común y en la forma como el derecho de autor se inscribe en éste, de manera que se pueda establecer mejor su papel en la definición del alcance de los intereses que confluyen en el régimen jurídico bajo estudio.

Sobre el particular, FinNis afirma que el bien común puede ser entendido desde tres perspectivas distintas, a saber: a) cada uno de los bienes humanos

\footnotetext{
${ }^{51}$ Cfr. Prólogo de Rodolfo Vigo al libro de Alfonso Santiago sobre el bien común y el derecho constitucional. En el mismo libro, su autor principal manifiesta que "[e]ı bien común ha de ser personalista y solidario, personalista por estar basado en la dignidad de cada persona y concebido para satisfacer sus necesidades de plenitud. Solidario porque la persona tiene vocación no sólo a vivir con el otro sino para el otro. Todos deben estar comprometidos con su logro y todos deben participar de sus beneficios", y que "[e]ı bien común es de modo análogo, un deporte grupal en el que el triunfo o la derrota es a la vez del equipo y de cada uno de sus integrantes, más allá de la actuación que haya tenido". Santiago, Alfonso. Bien común y derecho constitucional, Ábaco, Buenos Aires, 2002, pp. 12,24 y 96 , respectivamente.
} 
básicos, en cuanto ellos son buenos para todas las personas; b) la participación de cada una de esas personas de dichos bienes humanos básicos, y c) el conjunto de condiciones para alcanzar estos bienes. ${ }^{52}$ Previamente se han mencionado los principales bienes básicos de los que buscan participar tanto los autores como los usuarios cuando crean y disfrutan la obra, a saber: conocimiento y búsqueda de la verdad, trabajo, juego y experiencia estética. ${ }^{53}$ En la práctica, aunque defensores y detractores del derecho de autor justifican sus posiciones en la consecución de estos bienes y en la manera como se pueden lograr, al respaldar sus reivindicaciones desde distintas posiciones dentro del mismo liberalismo, cierran la puerta a consideraciones de bien común, contexto dentro del cual se superaría la polarización del debate y el conflictivismo de derechos. ${ }^{54}$

La protección que mereció el derecho de autor en los primeros estatutos pudo haberse justificado por la referencia al conocimiento como bien humano de primer orden. Una mirada a las normas iniciales sobre derecho de autor permite concluir que los derechos exclusivos que se reconocieron a los autores estaban fundados en motivos de utilidad: a mayor protección de los autores y sus obras, mayores incentivos para la promoción y difusión del conocimiento en la sociedad. Sin embargo, ha sido ampliamente discutida la forma como se pueden conseguir estos fines. Por un lado, los defensores del derecho de autor consideran que un mayor conocimiento es consecuencia de la producción de una mayor cantidad de obras, y que ello sólo es posible cuando existe un marco jurídico que otorga una debida protección al autor y a sus creaciones. Desde esta perspectiva, el sistema jurídico protector debe interpretarse de manera extensiva y preferente a favor del autor, y de forma restringida y limitada en relación con todas las demás personas que pretendan tener acceso a la obra. En particular, se sostiene que unos derechos más fuertes a favor del autor redundarán en un mayor estímulo para la creación de obras, mientras que su limitación a favor de

\footnotetext{
52 Cfr. FinnIS, John. Ley natural y derechos naturales, cit., pp. 183-185.

${ }_{53}$ Cfr. FinnIs, John. Natural Law and Natural Rights, 2a. ed., Oxford University Press, Nueva York, 2011, pp. 59-99; Hervada, Javier. ¿Qué es el derecho?, Eunsa, Pamplona, 2002, pp. 176 y 177. Aunque también pueden participar de otros bienes como la sociabilidad y amistad, la religión, etcétera.

${ }^{54}$ Serna y Toller consideran que, en realidad, no existen los conflictos de derechos, sino de pretensiones e intereses individuales. Los derechos nacen en armonía y adecuados entre sí, atendiendo al bien de la comunidad en la que se encuentran sus titulares. Cfr. Serna, Pedro y Toller, Fernando. La interpretación constitucional de los derechos fundamentales: una alternativa a los conflictos de derechos, cit., pp. 37-39. Por su parte, Cianciardo afirma que "[...] no es posible hablar de conflictos iusfundamentales. Los derechos, como objetos exigidos por la naturaleza humana, nacen ajustados unos con otros. La convergencia de intereses contradictorios sobre el mismo objeto no invalida la afirmación anterior, porque los intereses, las aspiraciones, no son per se derecho, y porque la sociabilidad forma parte de la naturaleza humana. Cada derecho no es anti-social, ni puede ser reconocido prescindiendo de las exigencias -básicas, en el caso de los derechos fundamentales- de las demás personas". CIANCIARDo, JuAn. El conflictivismo en los derechos fundamentales, cit., pp. 369 y 370 .
} 
terceros implicará un desincentivo a su labor creadora y, por tanto, a la generación de conocimiento..$^{55}$

Por otro lado, los críticos de los sistemas de derecho de autor propugnan por una significativa limitación de los derechos exclusivos de los autores y por una mayor o total libertad de utilización de sus creaciones, permitiendo así una amplia difusión del conocimiento. Esta posición está usualmente soportada en la prevalencia de los derechos fundamentales a la educación, a la información y a la libre expresión, entre otros. ${ }^{56}$ En los últimos años también se han ubicado en esta orilla de la discusión aquellos que buscan el reconocimiento de otros derechos "fundamentales" como el acceso al conocimiento - access to knowledge, o A2к por su denominación y siglas en inglés- y el acceso a Internet. ${ }^{57}$ Para todos ellos, el "conocimiento libre" se constituye en un poderoso motor de saber y transmisor de cultura, por lo que bajo esta concepción se alcanzarian mejor los fines de las sociedades democráticas, en cuanto más personas accederían a más fuentes de conocimiento y, en esa medida, habría más creadores y creaciones. ${ }^{58}$

En todo caso, una de las principales causas por las cuales los defensores y detractores de los sistemas de derechos de autor no logran un acuerdo sobre los mejores medios para promover el conocimiento es por la multiplicidad de intereses adicionales y contrapuestos de los distintos actores involucrados, y su falta de referencia a un bien común. En efecto, por más que se arguyan motivos de interés público en la protección de los derechos de los autores y de los titulares o en la mayor limitación de dichos derechos, si en los distintos miembros de la sociedad no se verifica la propia consecución de los bienes singulares relacionados (conocimiento, verdad, trabajo, juego, experiencia estética, etcétera) no se estaría logrando tampoco el bien común, como tampoco alcanzarían realmente esos bienes singulares si para su obtención no se ha buscado el bien común, sino la afirmación absoluta de sus propios intereses, olvidando que entre dos bienes auténticos no puede existir oposición. ${ }^{59}$ En suma, la discusión entre promotores y opositores de un derecho de autor menos limitado, entre enemigos y amigos

${ }_{55}$ Strowel desarrolla con amplitud esta justificación basada en el estímulo personal al autor y su eficacia económica e influencia en el mercado. StRoweL, ALAIN. Droit d'auteur et copyright: Divergences et convergences, Bruylant-LGDJ, Bruselas-Paris, 1993, pp. 173 y ss.; Vivant, Michel. "Le Droit d'Auteur, un Droit de I'Homme?", en Revue Internationale du Droit d'Auteur [RIDA] 174 (1997), 60, p. 69 y nota 10.

${ }^{56}$ Véase, por ejemplo, la descripción de los extremismos del copyright que hace LessiG, LaWrenCE. "The Creative Commons", en Montana Law Review 65 (2004), 1, p. 10.

57 Véase el reporte presentado a la Asamblea General de Naciones Unidas por Frank La Rue, relator para la promoción de la libertad de expresión y de opinión, 16 de mayo de 2011.

${ }^{58}$ VIVANT menciona y califica de poco serias estas posiciones que verian con buenos ojos la desaparición del derecho de autor, entendido como un obstáculo para el libre desarrollo del conocimiento. Vivant, MicheL. "Le Droit d'Auteur, un Droit de l'Homme?", op. cit., p. 69 y nota 12.

${ }^{59}$ Cfr. Vigo, Rodolfo L. Las causas del derecho, cit., p. 169. El autor retoma conceptos de la filosofía aristotélico-tomista para afirmar la imposibilidad de obstrucción entre dos bienes, cuando ellos son verdaderos y parte del bien común. 
de una mayor libertad en la utilización de obras y creaciones, se torna insalvable cuando ella se sustenta en el supuesto carácter absoluto ${ }^{60}$ de los derechos e intereses que cada uno pretende defender. El debate, así planteado, deja de ser jurídico y racional y se transforma en mediático y visceral. ${ }^{61}$

En el trasfondo de este debate se evidencia, bajo el rótulo de "interés público", la preocupación común por conseguir, aumentar y difundir el conocimiento en la mayor proporción posible. Sin embargo, las posturas en cuestión difieren en cuanto a los medios que se requieren para lograr este fin y, al calificar a estos medios como derechos absolutos, dificultan su final consecución. ${ }^{62}$ Para resolver esta cuestión, se requiere de un acuerdo básico sobre los intereses y valores que comúnmente se quieren conseguir con un régimen autoral más o menos estricto, con unas libertades de información, expresión, etcétera, más o menos amplias. Es preciso definir el contenido del bien común relacionado con estos derechos e intereses y la forma como él puede ser obtenido. ${ }^{63}$ Así, en la medida que se logre una mayor identidad de pretensiones relativas a la creación y aprovechamiento de las obras, se obtendrá un vínculo unificador más fuerte y aumentará la probabilidad de satisfacer esas aspiraciones compartidas, redundando en beneficio de unos y otros.

Un acuerdo sobre este particular debe partir del entendimiento sobre el fin que se quiere lograr en conjunto y la manera como el derecho de autor y sus limitaciones pueden contribuir al bienestar integral de la sociedad, acrecentando

\footnotetext{
${ }^{60}$ El que los derechos e intereses involucrados en este debate se encuentren soportados en bienes humanos básicos no significa que ellos, por sí mismos, sean bienes humanos básicos. Adicionalmente, se debe tener en cuenta que no debe existir ninguna preferencia arbitraria entre valores o bienes humanos básicos. Cfr. FinNIS, JoHN. Ley natural y derechos naturales, cit., pp. 137-140.

${ }^{61}$ En la línea de pensamiento de Cruz Prados, se puede criticar esta clase de posturas como típicamente liberales individualistas, que terminan convirtiendo un problema práctico en un verdadero conflicto de derechos, otorgando mayor importancia al interés de cada cual, que a los fines comunes hacia los cuales deberían estar encaminados. Cfr. Cruz Prados, Alrredo. Ethos y polis: bases para una reconstrucción de la filosofía política, 2a. ed., Eunsa, Pamplona, 2006, pp. 108 y 109.

62 Para WRIGHT, el mismo concepto de interés público incorpora una contradicción que tiende a polarizar el debate. Por un lado, se considera que el interés público se sirve mejor protegiendo los intereses de los autores y titulares para estimular la producción de obras, mientras que por el otro se considera que las limitaciones a tales derechos a favor de un mayor acceso al conocimiento por parte de la sociedad favorece dicho interés público. WRIGHT, RoBIN. "The 'Three-Step Test' and the Wider Public Interest: Towards a More Inclusive Interpretation", en Journal of World Intellectual Property 12, No. 6 (2009), p. 600.

${ }^{63}$ Sin la definición de un ethos común en materia de propiedad intelectual no será posible definir qué postura y qué acción es racional. Sobre este tema, Cruz Prados señala: "Para que quepa racionalidad práctica, es preciso la previa definición del ethos común, de lo que estamos haciendo juntos. Frente al normativismo, hay que afirmar que la definición del ethos precede y es condición de la formulación de las normas [...] El ethos no es una trama normativa, ni se constituye por suma de normas. Es algo que estamos haciendo, una praxis común; una forma real y concreta -y más o menos abarcante- de actividad compartida, de vida común. Las normas, como auténticas reglas prácticas, sólo pueden surgir a partir de aquello en lo que consista el ethos". CRuz Prados, Alfredo. Ethos y polis: bases para una reconstrucción de la filosofía política, cit., p. 111.
} 
y transformando lo que los distintos actores hagan individualmente, perfeccionando y conjugando sus fuerzas singulares de forma que los bienes que genera la creación y el disfrute de obras sean participados a toda la comunidad, en el máximo grado posible.

En suma, el bien común supone, en el caso del derecho de autor, la ordenación de los distintos bienes individuales hacia un fin común para todos los actores involucrados; ${ }^{64}$ por ejemplo, una justa retribución al trabajo realizado por el autor, el reconocimiento de la autoría de una obra o la posibilidad de acceder a la obra y usarla en condiciones equitativas, esto es, pagando un precio razonable o disfrutándola sin pago, según dicten las circunstancias particulares. El bien común es integral y armonizador, debe ayudar a que se realicen plenamente las distintas facetas de la vida humana, por lo que, en el caso del derecho de autor, debe abarcar y procurar la efectividad de derechos tan aparentemente disímiles, como la cultura y la propiedad, la libertad de expresión y la honra. Y respecto a cada uno de ellos, atendiendo a las específicas circunstancias históricas y sociales, el bien común influirá para que la obtención de los bienes relacionados sea perfectiva y gradual, de unos bienes básicos a unos intermedios, y a otros más elevados. Así, el sistema de derecho de autor deberá permitir pasar de un nivel básico de educación a garantizar un desarrollo tecnológico más avanzado; ${ }^{65}$ de estimular la creación de ciertas obras a incentivar, mediante políticas más ambiciosas y comprehensivas, la producción y disfrute masivo de las creaciones intelectuales.

Ahora bien, cabría preguntarse si el mismo concepto de bien común que se ha planteado aplica también para la comunidad internacional o, lo que es igual, si tal idea de bien común puede llegar a justificarse en el marco del orden internacional creado con los procesos de integración interestatal. Robert P. George arguye en sentido afirmativo sobre la base de dos premisas fundamentales: en nuestros días, el Estado nacional es incapaz por sí solo de realizar todas las condiciones necesarias para garantizar el bienestar global de sus ciudadanos, cuestión que se corrobora con una mirada a las problemáticas actuales de las que se deduce la necesidad de la cooperación internacional, por un lado, y el desarrollo de instituciones supranacionales para darles efectiva solución, por otro. ${ }^{66}$ En el mismo sentido, FinNIS afirma:

\footnotetext{
64 Sobre el particular, Vigo afirma que "son los mismos miembros de la comunidad, a través de sus diferenciados talentos y funciones, los encargados de forjar y de usufructuar el bien común, además de lograr sus respectivos bienes individuales". VIGo, Rodolfo L. Las causas del derecho, cit., p. 169.

${ }^{65}$ Una idea similar, aunque de manera general, se propone en la siguiente obra: SAntiago, Alfonso. Bien común y derecho constitucional, cit., p. 116.

${ }^{66}$ Cfr. George, Robert P. Entre el derecho y la moral, trad. de Pedro José Izquierdo Franco, Universidad Javeriana, Editorial Ibañez, Bogotá, 2009, colección Internacional, vol. 14, pp. 83-85.
} 
Si ahora nos encontramos con que el bien de los individuos sólo puede ser plenamente asegurado y hecho realidad en el contexto de la comunidad internacional, tenemos que concluir que la pretensión del Estado nacional de ser una comunidad completa es injustificada y el postulado del orden jurídico nacional, concebido como supremo y comprehensivo y como fuente exclusiva de obligación jurídica, es crecientemente lo que los juristas llamarían una "ficción jurídica". ${ }^{67}$

La realidad del momento histórico al que asistimos permite concluir, entonces, que el concepto de bien común no se encasilla en el marco que ofrecen los escenarios nacionales, sino que los mismos Estados aparecen como una asociación intermedia que se ubica entre el individuo y la comunidad más amplia, que sería la internacional. Conviene advertir que, en todo caso, de conformidad con el principio de subsidiariedad, las autoridades internacionales son esenciales para formar una comunidad completa, pero no están pensadas para desplazar a las autoridades nacionales o locales, sino para actuar ayudando, supliendo o hasta corrigiendo las limitaciones de las autoridades nacionales. ${ }^{68}$

Acogiendo esta perspectiva, no sólo es posible sino deseable alentar una revisión de los procesos de integración interestatal a la luz de la noción de bien común defendida, como condición de una verdadera cooperación internacional -motivación expresa que sustenta todos los tratados que fomentan el comercio internacional-. En este sentido se orientan algunas reflexiones circunstanciadas a los tratados del ADPIC, TPP, ACTA y Marrakech, que se expondrán en el colofón.

\section{Colofón: algunas consecuencias prácticas de la conjugación del derecho de autor y el bien común en los procesos de integración económica}

La introducción del concepto de bien común en los principios que sustentan el derecho de autor, permite comprender que las limitaciones o excepciones le son connaturales; por tanto, no son imposiciones derivadas de un interés general que se erige por encima de los intereses individuales de los autores. Al mismo tiempo, la lógica del bien común, en el contexto de la interacción del derecho

\footnotetext{
${ }^{67}$ Finnis, John. Ley natural y derechos naturales, cit., p. 179.

68 Sobre el principio de subsidiariedad y sus implicaciones véase CarozzA, Paolo. "Subsidiarity as a Structural Principle of International Human Rights Law", en Am. J. Int'I L. 97, No. 1 (2003), 38. El autor alli afirma que el principio de subsidiariedad supone "intervention by the state in situations where 'lower' forms of organization cannot achieve their ends by themselves. In fact, subsidiarity insists not only that the state may intervene in such situations, but that it has 'an inherent right' to concern itself with the common good and indeed a duty to exercise that right". Análogamente, puede aplicarse la misma noción para justificar los procesos de integración regional, sustentados en primera instancia por el fin que une a los actores de estos acuerdos: la consecución del bien común.
} 
de autor y otros derechos humanos, exigirá la ordenación de los diversos bienes individuales hacia fines que beneficien a los distintos interesados, como pueden ser el reconocimiento de la autoría de una obra y la correspondiente retribución al autor, pero también la posibilidad de acceder a la obra y usarla bajo determinadas condiciones. El bien común se constituirá entonces en un elemento armonizador en los diferentes sistemas de protección de las creaciones intelectuales.

En el caso de los procesos de integración económica en los que se prevean aspectos relacionados con el derecho de autor, no basta con acordar elementos que puedan ayudar a la consecución del bien común sino que, además, se deben hacer efectivas las flexibilidades que se encuentran dispuestas en los diversos instrumentos internacionales, tales como las mencionadas en la primera parte de este escrito: las referencias en el preámbulo y en los artículos 7 y 8 del ADPIC al favorecimiento del bienestar social y económico, y al equilibrio de derechos y obligaciones, así como a la prevención del abuso de los derechos de propiedad intelectual y la "regla de los tres pasos" que permite el establecimiento de limitaciones y excepciones; las menciones en ACTA al equilibrio de derechos e intereses de titulares y usuarios, así como al respeto de los principios fundamentales protectores de la persona; lo previsto en el TPP en cuanto al equilibrio que debe buscarse mediante la consagración de limitaciones y excepciones, su extensión al entorno digital y la consideración de propósitos legítimos como los del fair use; la propuesta del tratado sobre limitaciones y excepciones a favor de personas con discapacidad visual, construida en el marco general de los derechos humanos y de los criterios de la agenda para el desarrollo, promovida por la omPl.

En la práctica, lo anterior debería conducir a un abanico más amplio de limitaciones y excepciones acordes con el bien común, así como a hacer uso de las flexibilidades que hoy en día ya están previstas, y a interpretar las disposiciones de los tratados de integración económica con ese mismo criterio de flexibilidad, de forma tal que juicios de razonabilidad como la "regla de los tres pasos" puedan ser interpretados adecuadamente, permitiendo a cada país signatario adaptar las disposiciones generales a su propia realidad social y a sus correspondientes necesidades locales. 